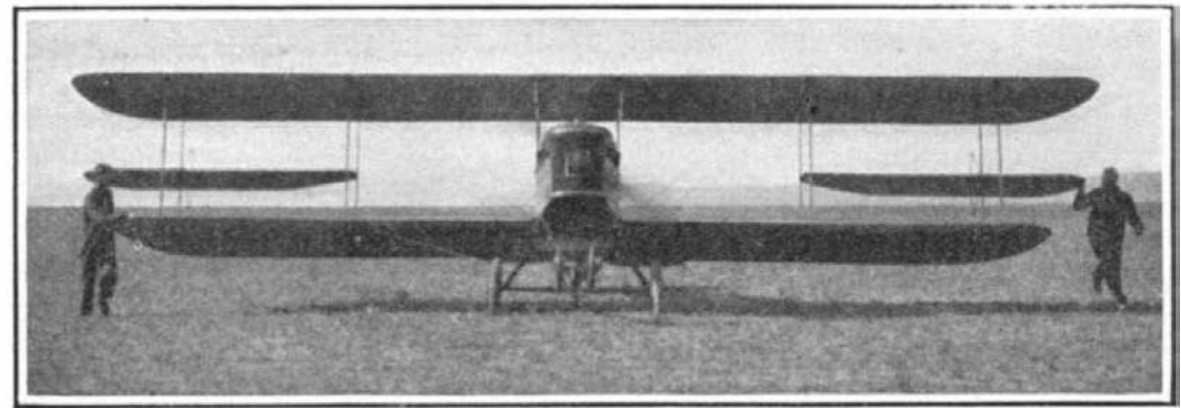

“Trimming" a military tractor in leaving the ground A military tractor biplane just before leaving the ground. In gusty weather the mechanicians
steady the ends of the lower planes, sometimes turning the machine by

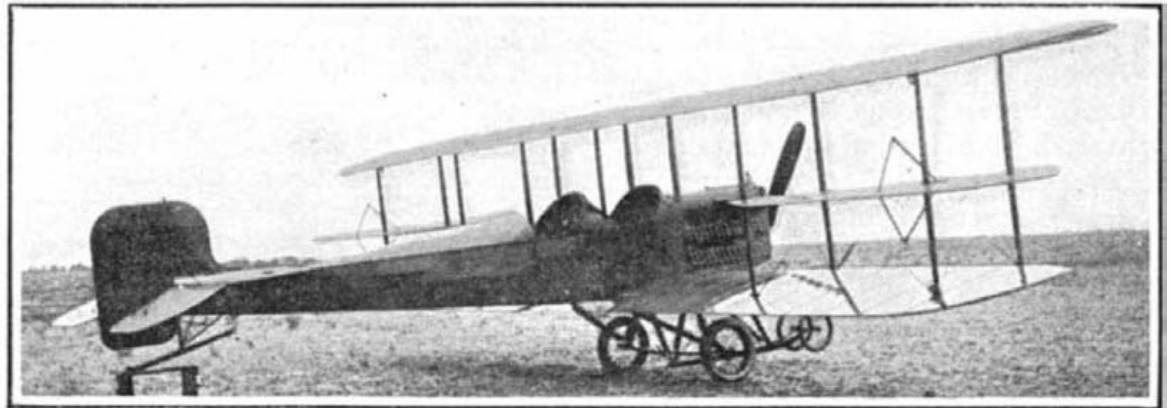

The Glenn Martin type of biplane used at the San Diego school The flying radius of this machine with normal equipment and two passongers is 300 miles.
It has an 80 -horsepower engine, a wing soread of 38 feet 10 incnes, and

\title{
Airmen and the Weather Bureau-Partners
}

\section{The Meteorological Work Undertaken at the San Diego Army Aviation School}

By C. L. Edholm

CLOSE coöperation between the United States Weather Bureau and the Army aviators is indicated by a report of the forecaster, Dr. Ford A. Carpenter of Los Angeles, regarding the activities of his office in connection with the War Department school of aviation at San Diego, in southern California. That the interest of this distinguished meteorologist in aviation is not merely academic was demonstrated recently when he made a flight from the school on North Island, in order to study at first hand certain dangerous wind conditions which are usually to be found over Point Loma. This is the first time that a United States weather observer has made an aeroplane flight, and it was done partly to ascertain by experience the problems that confront the flier and so to be of greater service in helping solve these problems.

For many years the relations between the weather man and the airman have been mutually helpful. The laboratories for the study of the upper air have secured information of the greatest value regarding air currents, their direction and velocities at levels up to twenty and one-half miles, as well as the temperatures encountered at various altitudes. In 1914 the Weather Bureau and the Army Aviation School coöperated officially for the first time when Dr. W. J. Humphreys, Professor of Meteorological Physics, was detailed to deliver a series of lectures at the school, one of which, "Holes in the Air," has been reprinted for use there as a text book. Previous to that date, however, there had been active though unofficial coöperation; in fact Dr. Carpenter's knowledge of weather conditions at San Diego was of value in helping select the site for the school on North Island, a location which is ideal for beginners because of its climatic as well as topographical advantages.

Gradually the Weather Bureau and the Aviation School have come in touch until now there is hardly a day without a conference between the officer-instructors and the forecaster. During the cross-country flights of April and May, 1916, forecasts of flying conditions were issued to the aviators. Special observations of wind, weather and fog conditions were made from the coast near Los Angeles, and from the Weather Bureau coöperative station at the Mount Wilson Solar Observatory. From the latter point, with an altitude of 6,000 feet, reports of fog heights were secured, which were of particular value. This station commands a sweeping view of the coast from Point Firmin, overlooking Los Angeles harbor, to Point Loma on San Diego Bay. Knowing the different levels, the observer stationed on Mount Wilson was able to report the actual thickness and

extent of the fog belt, its history for the previous twentyfour hours, and a satisfactory forecast regarding it.

Not content with receiving and analyzing the daily weather forecasts, the officers at North Island are teaching the fundamentals of meteorology to the students of aviation. Lectures are given on temperature and its distribution, and on winds, moisture and clouds, one of the text books being a reprint of "Clouds of California," a weather bureau paper by Dr. Carpenter. The Bureau has furnished a standard set of meteorological instruments for use at the station, in order to familiarize the airmen with the equipment and its use. The application of this theretical knowledge to the wind and weather conditions encountered in their daily flights, forms part of the training of the fliers.

One of the staff instructors investigated varying wind directions, making use of small parachutes which are dropped at various altitudes. Duplicate signal sheets

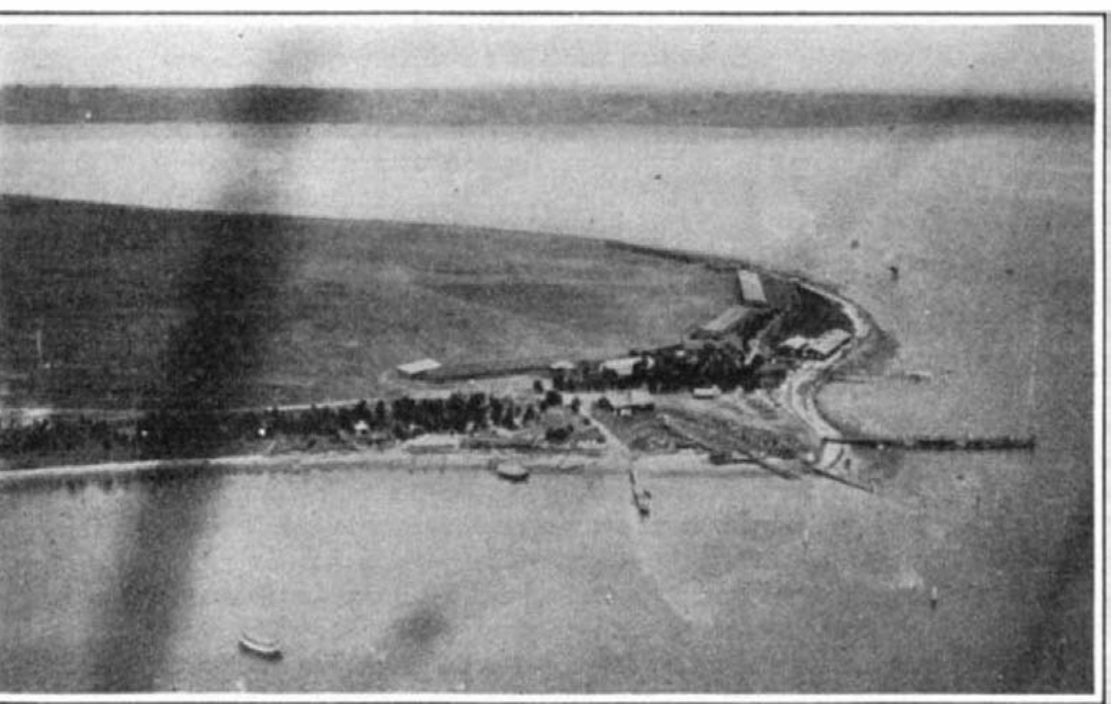

United States aviation field at San Diego, Cal., at 2,000 feet altitude

of a scientist who had for twenty years studied conditions from the ground and from the records of balloons sent aloft with recording instruments. Fifteen years ago Dr. Carpenter began his study of aviation at San Diego, assisting Octave Chanute, who made photographs and observations of the flight of gulls and pelicans, developing facts which the Wright brothers put to use in their designs. Since then his association with the Wrights and Curtiss has kept him in intimate relation with the science, but in spite of that he felt that the weather man who is to be of most assistance to the airman must have actual experience in flying. Besides getting the aviator's point of view, Dr. Carpenter had the specific object of ascertaining the height of the upward trend of a certain treacherous wind over Point Loma, an area which is shunned by the novice. Also he desired to observe the extent, form and composition of the velo cloud, the characteristic sun cover of California.

The ascent was made in one of the tractors used at the Aviation School, an 80 horse-power machine made by Glenn Martin in Los Angeles. Captain Oscar Brindley, 1915 winner of the Curtiss trophy, was pilot. The propeller was started and the machine headed into a 30 -mile wind and in a few seconds the aeroplane was ascernding at a gradient of one to seven. Very soon an altitude of 3,000 feet was reached and then, according to the plan, the aeroplane was plunged into the "aerial breakers" over Point Loma. This ridge that projects into the Pacific at an altitude of 500 feet deflects the prevailing northwesterly wind upwards, and causes disturbances that arefelt by aviators and seamen alike. Topsails of schooners have been carried away by these twisting air currents, which are known locally as "woolies," because they churn the surface of the water into isolated patches of foam like tufts of wool. Seen from the aero-

ere provided by the Bureau station at San Diego, from which the student-officers make their own weather maps. From them and from their own flights, they could arrive at some relationship between the actual and theoretical 3,000 and 10,000-foot level maps prepared by the Bigelow formula, as used by the Bureau.

By placing at the fliers' disposal the information gathered by the meteorologists, and by instructing the aviators in the fundamentals of the science, so that they apply the information to the problems encountered in flight, the Weather Bureau adds greatly to the efficiency of our airmen and lessens the dangers of their calling.

The final link in the chain of service between th plane, Point Loma looked like the backbone

of some monstrous foint Loma looked like the backbone approach into the disturbed area was presently felt. The tractor shivered under the impact of two distinct blows, as perceptible as though the fuselage had been struck with a stuffed club. There was a surge and then a sudden drop, for a descending current had been encountered that deprived the aircraft of support. This condition has been observed by aviators as high as 4,000 feet, though the ridge that causes it has a height of only 500 feet.

The aeroplane was making a speed of 70 miles an hour against a 30-mile wind, and as the pilot prepared to change the course, the observer felt some apprehension, (Concluded on page 355)

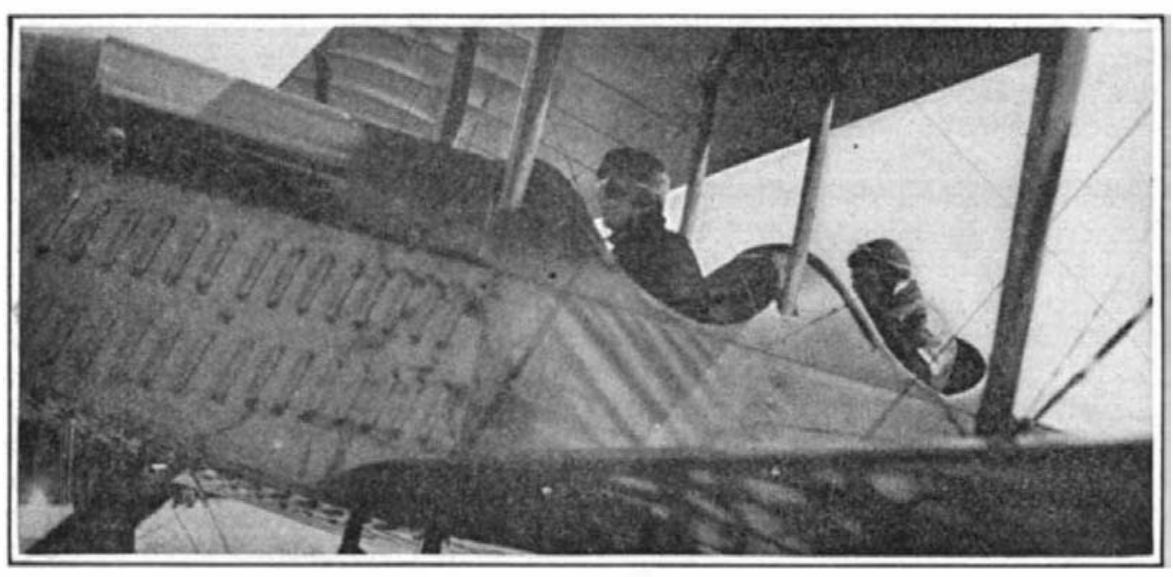

Instructor Brindley and Meteorologist Carpenter starting on a flight In cranking an aeroplane engine the aviator short-circuits the ignition system while the
mechanician turns the propeller to introduce the explosive mixture into

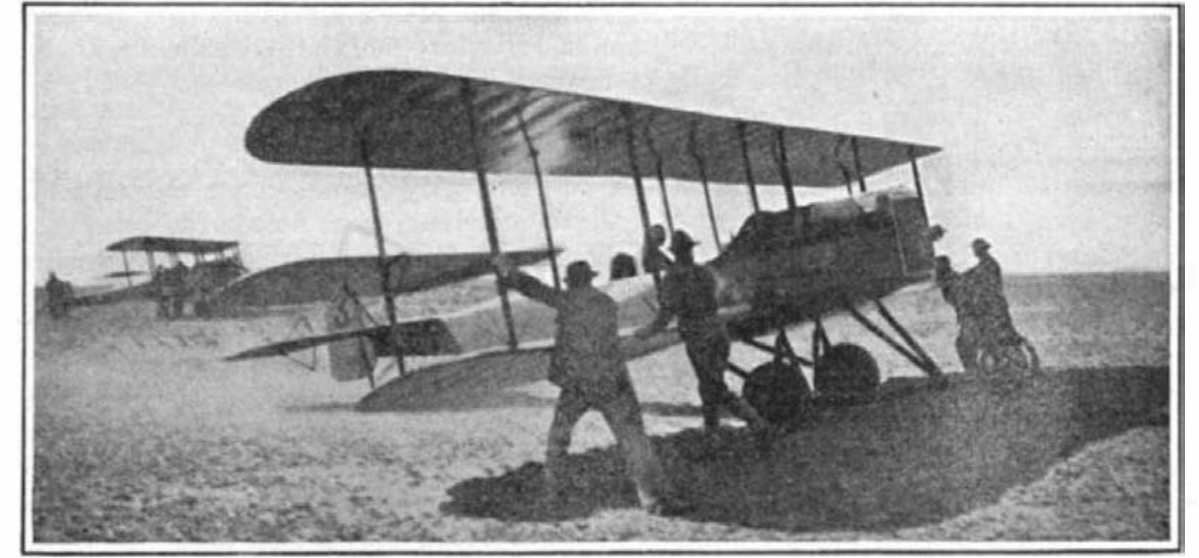

Lieut. H. A. Dargue testing his engine before flight The power of the engine is observed by the clouds of dust kicked up by the propeller, and
the energies of the four men that are required to keep the machine 
The Heavens in April, 1917 (Concluded from page 347 )

the meridian, and on the right a small but conspicuous quadrilateral, whose upper edge points toward the bright star first mentioned. The small group is Corvus, the Raven, while the bright star, Spica, is the principal luminary of Virgo. High up in the southeast is Leo, marked by the familiar sickle, and the second magnitude star Denebola in the hindquarters. Arcturus, the brightest star in sight, forms a fine large triangle with Denebol $r$ and Spica. Below Arcturus in the southeast are Ophiuchus and Serpens, and the head of Scorpio is rising. The bright star low in the northeast is Vera, and Hercules and Corona may be found on the line joining this to Arcturus. In the north we find Cassiopeia and Cepheus below the pole. Ursa Minor and Draco, higher up in the north-northwest and the Great Bear almost overhead. Auriga and Gemini are the most conspicuous constellations in the northwest and west, and Canis Minor is to the left of the latter. The ungainly length of Hydra, extending from near Procyon to a point below Spica, bring us back to our starting point.

$$
\text { The Planets }
$$

Mercury is an evening star this month, and is best visible towards its close, being at greatest elongation, $20^{\circ}$ east of the Sun, on the 24th. At this time lie is on the borders of Aries and Taurus, and $21^{\circ}$ north of the equator, so that he remains in sight until 8:30 P. M. At the end of the month he is very near the Pleiades, and is still easily visible just after dark. $\mathrm{He}$ is as bright as Procyon, or brighter, and exceeds any star within a long distance. This is an unusually good chance to see him, and one which the amateur should not miss.

Venus is in superior conjunction behind the Sun, on the 26th, and is invisible this month.

Mars is a morning star, but so near the Sun as to be practically invisible. Jupiter is an evening star, setting at 8:30 P. M. on the 1st, but is lost in the twilight before the end of the month. On the 16th, he is in conjunction with Mercury-the latter being $3^{\circ}$ to the northward. The two planet should form a pretty pair in the twilight.

Saturn is in quadrature with the Sun on the 14th, and may be considered an evening star, though he does not set till 1:30 A. M. Uranus is a morning star in Capricornus, rising about $3 \mathrm{~A}$. M. and hard to observe. Neptune is in Cancer, almost stationary in the heavens, remaining all through the month within about $2^{\prime}$ of arc of the position $8 \mathrm{~h} .17 \mathrm{~m} .20 \mathrm{~s} .+19$

$29^{\prime}$. He is observable on the early evening.

he Moon is full at $10 \mathrm{~A}$. M. on the 7 th in her last quarter at $3 \mathrm{P}$. M. on the 8 th new at $9 \mathrm{~A}$. M. on the $21 \mathrm{st}$, and in her first quarter at midnight on the 28th. Sh is nearest the earth on the 18th, and farthest away on the $2 \mathrm{~d}$ and 30 th. Durin the month she passes near Neptune on th 1 st, Uranus on the 16th, Mars on the 20th Venus on the 21st, Jupiter and Mercury on the $22 \mathrm{~d}$, Saturn on the $27 \mathrm{th}$, and Neptune again on the 28 th.

\section{Mellish's Comet}

A telegram received this morning announces the discovery of a comet by Mellish in right ascension 2h. $7 \mathrm{~m}$., declination $14^{\circ}$ north. Nothing but thi rough position is as yet in hand, and $n$ prediction can therefore be made regarding the future visibility of the comet. Th discovery-position is about $3^{\circ}$ west and $1^{\circ}$ north of Jupiter, which should at present serve as an easy mark for finding it in the western sky.

Princeton University Observator March 21st, 1917.

Airmen and the Weather BureauPartners

expecting the craft to heel at an uncomfortable angle as it was brought around. Nothing of the sort occurred; as Dr. Carpenter remarks, "Theoretically one may be ever so well grounded in physical laws, but it seems to take actual experience to bring their truth home to us. Of course there can be no wind in the air; when we entered the air it was moving 30 miles \begin{tabular}{l|l|} 
we entered the air it was moving 30 miles & total time aloft of 1,516 hours, work pro- \\
an hour in relation to the earth but as soon & gressing regardless of weather conditions
\end{tabular} as we were free of the earth, the velocity of the wind had no effect on our flight. No matter how strong the gale, so far as it concerns our aeroplane, if the wind be teady, no difficulty is experienced; the viator is concerned only by wind-shifts." This comment explains the practical value of sending aloft such scientists as deal with aviation matters, as a first hand nowledge of conditions gives weight to their research that no amol

The plunge through the velo cloud was mertaken next and it was observed to be our or five hundred feet thick, with a agged edge extending inland, while its eaward edge was clean cut and lay parallel with the coast for ten or fifteen miles. here the vision was not obscured by the , objects could be seen with remarkdiscerned easily at a distance of 20 miles, e city and the aviation school were harply defined in every detail and the bay and ocean were absolutely transparent to the bottom. No submarine could hope to hide from an aerial observer any more than it could if the water were swept from the sea, for objects under the surface

Thetly visible from the aeroplan

The descent was made in wide spirals, and in connection with the landing, Dr. Carpenter remarks on the little known fact that the color of the landing place has its effect upon the machine. Land which is dark from being plowed or burned ove will heat the air above it faster than will field of stubble, the difference being due to the varying absorption and reflection of sunlight. A landing place which has an area of heated air above it is dangerous, as the air disturbance gives insecure support for the planes. One of the aviators told f attempting such a landing and being tossed upward by a warm current when he had almost reached the ground.

The thorough manner in which the school on North Island is attempting to solve the airman's problems is quite in keeping with its past history. It was established in 1911 and has been the scene of several important achievements. Here as flown the first seaplane by Glenn Curtiss; from here various cross-country flights were made, and a recent flight of importance was an altitude record. In February 1916, a California-built tractor eaplane carrying three passengers reached an altitude of 12,362 feet, the best previous record for similar conditions being 9,000 feet. This machine has a 125 horse-powe motor and carried besides the three men, 26 gallons of gasoline and four gallons of oil, total weight of 3,100 pounds.

The location of the school is ideal. North Island is really not an island, but is connected by a narrow sand spit with the Coronado Peninsula. Across the Bay is San Diego to the north, the Pacific Ocean is to the south, and the narrow entrance to the harbor is to the west. There is an area of hundreds of acres, free of wires or other overhead obstructions, so that the novice has here an opportunity for flying over clear land and operating the seaplanes upon rough water and smooth.

The period of probation for officers who volunteer for aerial instruction is less than ninety days. In that time, if his superiors consider that he lacks the temperamental qualities of caution and judgment, he is weeded out. The technical skill may be acquired, but the airman's temperament is born in him. An essential feature of the course is detail in the repair shop, and the gas engine is studied both for motor truck and aeroplanes. Flying is done in the early morning hours and there are lectures twice a day. The machines are equipped with dual control, so that the instructor can take charge of the aeroplane in an emergency. After each flight with a pupil, the instructor reviews point by point the details of the practical lesson just completed, pouncing on every error and explaining the correct procedure. The urse is one of hard work and hard think, and only first-class men can complete it During 1915 the students made 3,652 fights, with a mileage of 95,000 and a
total time aloft of 1,516 hours, work pro-

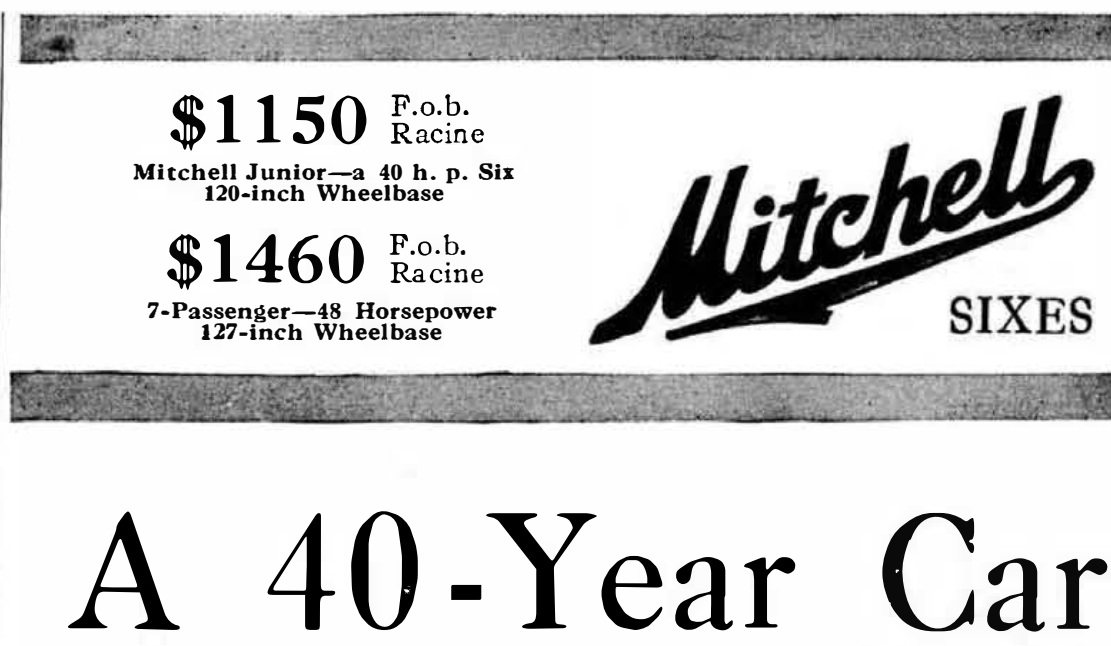

Several Mitchells, built by $\mathrm{Mr}$. Bate, have run over 200,000 miles. That's about 40 years of ordinary service.

But now Mr. Bate has doubled most of his margins of safety. Every vital part has 100 per cent overstrength. So any Mitchell, with ordinary care, should render lifetime service.

Over 440 parts are built of toughened steel. All safety parts are vastly over-size. Many parts are built of Chrome-Vanadium.

Gears are tested for 50,000 pounds per tooth. Engines must run, under heavy load, for 10,000 miles without wear. In two years not a single rear spring has broken.

\section{No Extra Cost to You}

All this added strength means no extra cost to you. All the Mitchell extras are free. Yet they include

\section{1 unique features-} $24 \%$ added luxury$100 \%$ over - strength.

There are 31 featureslike a power tire pump-

\section{The New $\$ 1150$ Model}

This year we build two sizes-Mitchell and Mitchell Junior. Even the smaller Six is roomy and powerful. You never saw such a car at this price.

All these marvelous values are due to John W. Bate, the famous efficiency expert. He built and equipped this mammoth plant to build this one type economically. His methods will save us, on this year's output, at least

$\$ 4,000,000$. That saving pays for all these extras. No other fine car offers anywhere near such value.

Go prove these facts, in justice to yourself. They are bound to win you to this Bate-built car.

MITCHELL MOTORS COMPANY, Inc. Racine, Wis., U. S. A

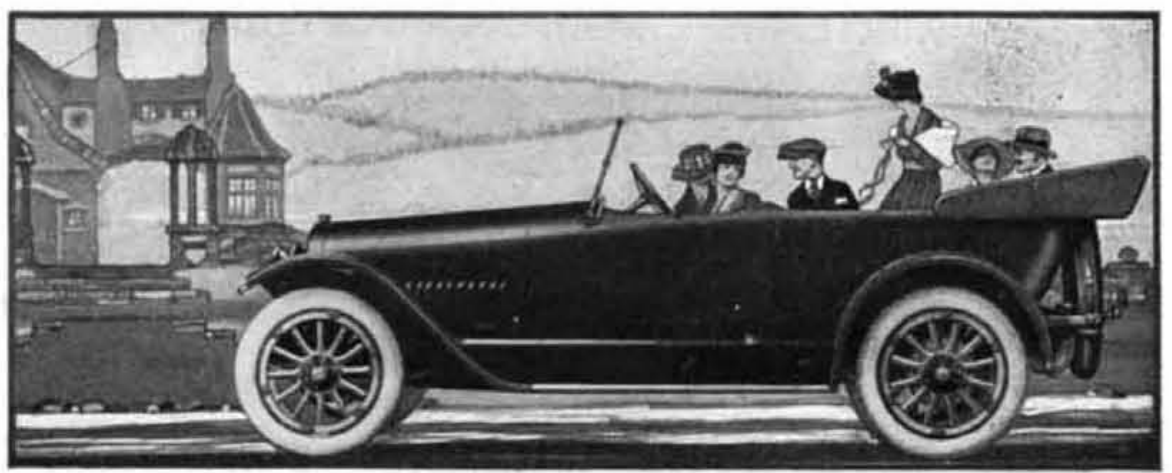

